Ekawati, R.

\title{
Pertumbuhan dan produksi pucuk kolesom pada intensitas cahaya rendah
}

\section{Growth and yield of kolesom shoot at low light intensity}

Diterima : 11 Desember 2017/Disetujui : 18 Desember 2017 / Dipublikasikan : 30 Desember 2017 CDepartment of Crop Science, Padjadjaran University

\begin{abstract}
Low light intensity is a one of environmental external factors could effect on the plant growth. The optimum light intensity can increase the plant growth. Kolesom is a functional vegetable that is used as medicinal plant. This research was aimed to determine the effect of low light intensity on shoot growth and yield of kolesom. This experiment was conducted at Politeknik LPP Yogyakarta, from March to September 2016. The experiment was arranged in randomized block design with single factor with two treatments (N0: without shading and N1: shading). Each treatment was repeated three times. The result showed that low light intensity (shading $82.51 \%$ ) treatment could decrease plant height and number of kolesom branch. The shading treatment displayed more width of kolesom leaf than without shading. However, the shading treatment decreased number of shoot, wet and dry biomass weight of kolesom than without shading.
\end{abstract}

Keywords: biomass, relative growth rate, shading, Talinum triangulare

Sari Intensitas cahaya rendah merupakan salah satu faktor eksternal lingkungan yang dapat mempengaruhi pertumbuhan suatu tanaman. Intensitas cahaya yang optimal dapat meningkatkan pertumbuhan tanaman. Kolesom merupakan salah satu jenis sayuran fungsional yang dapat digunakan sebagai tanaman obat. Penelitian ini bertujuan untuk mempelajari pengaruh intensitas cahaya rendah terhadap pertumbuhan dan hasil pucuk kolesom.

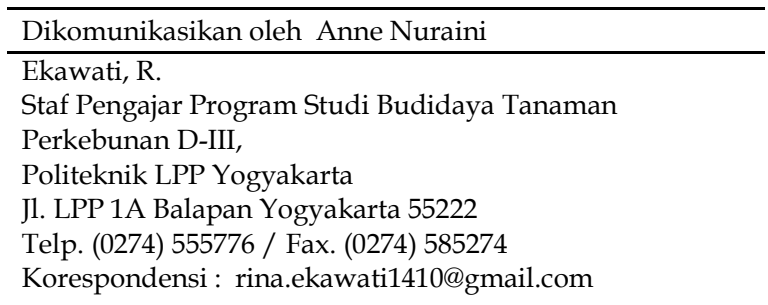

Percobaan ini dilakukan di Politeknik Lembaga Pendidikan Perkebunan (LPP) Yogyakarta, dari bulan Maret hingga September 2016. Penelitian ini menggunakan rancangan acak kelompok faktor tunggal dengan 2 taraf perlakuan, yaitu tanpa naungan (N0) dan naungan (N1). Setiap perlakuan diulang tiga kali sehingga terdapat 6 satuan percobaan. Hasil percobaan menunjukkan bahwa intensitas cahaya rendah (naungan paranet $82.51 \%$ ) dapat menekan pertumbuhan dan hasil pucuk kolesom. Naungan menurunkan tinggi tanaman dan jumlah cabang kolesom. Daun kolesom yang ternaungi lebih lebar jika dibandingkan tanpa naungan. Naungan menurunkan jumlah pucuk, bobot basah dan kering biomassa, tetapi meningkatkan bobot per pucuk kolesom.

Kata kunci: biomassa, laju tumbuh relatif, naungan, Talinum triangulare

\section{Pendahuluan}

Kolesom (Talinum triangulare (Jacq.) Willd) atau lebih dikenal dengan nama Ginseng Jawa atau Kolesom Jawa merupakan salah satu tanaman hortikultura yang bisa dijadikan sebagai tanaman sayuran dan berkhasiat obat. Seluruh bagian tanaman mulai dari akar hingga daunnya, bisa dimakan. Daunnya biasa dijual sebagai sayuran. Daun kolesom bisa ditemukan di pasar tradisional atau supermarket dengan harga terjangkau dengan harga Rp 5.500,00 per 250 g pada tahun 2016.

Daun kolesom juga mengandung senyawa flavonoid, asam fenolat dan antosianin yang berfungsi sebagai antioksidan. Flavonoid termasuk kelompok dari senyawa fenolik (Mualim, 2012). Menurut Ververidis et al. (2007) antosianin merupakan bagian dari komponen senyawa flavonoid yang berfungsi sebagai antioksidan dan cardioprotective. 
Salah satu faktor lingkungan yang mempengaruhi pertumbuhan tanaman adalah cahaya. Cahaya merupakan faktor penting bagi pertumbuhan dan perkembangan tanaman karena selain berperan dominan pada proses fotosintesis, juga sebagai pengendali, pemicu, dan modulator respons morfogenesis, khususnya pada tahap awal pertumbuhan tanaman (McNellis dan Deng, 1995 dalam Sopandie, 2013). Spektrum cahaya yang dibutuhkan tanaman berkisar antara panjang gelombang $400-700 \mathrm{~nm}$, yang biasa disebut photosynthetically active radiation (PAR). Intensitas cahaya yang optimal akan meningkatkan pertumbuhan tanaman. Menurut Salisbury dan Ross (1995), intensitas cahaya yang tinggi akan meningkatkan kadar karotenoid serta kandungan nitrogen sehingga mengakibatkan permukaan daun menjadi lebih terbuka, namun intensitas cahaya yang sangat tinggi dapat menurunkan kadar klorofil daun.

Chozin et al. (2000), Taiz dan Zeiger (2002) menyatakan bahwa daun yang ternaungi memiliki total klorofil tiap pusat reaksi yang lebih banyak, memiliki rasio klorofil b/a yang lebih besar, daunnya lebih tipis, sel-sel palisade lebih pendek dan konsentrasi rubisco lebih sedikit. Daun yang ternaungi mempunyai laju fotosintesis yang lebih rendah daripada daun yang tidak ternaungi. Titik kejenuhan akan cahaya pada sun plant 10-20 mol $\mathrm{m}^{-2} \mathrm{~s}^{-1}$ dan shade plant sekitar 1-5 mol m $\mathrm{m}^{-2} \mathrm{~s}^{-1}$. Nilai kejenuhan cahaya tanaman shade plant lebih rendah karena laju respirasinya sangat rendah sehingga dengan sedikit saja fotosintesis netto dihasilkan telah cukup membuat laju pertukaran netto $\mathrm{CO}_{2}$ menjadi nol. Laju respirasi yang rendah menunjukkan bentuk adaptasi tanaman bertahan terhadap lingkungan dengan cahaya yang terbatas.

Perlu untuk dilakukan penelitian mengenai pengaruh intensitas cahaya rendah terhadap respon pertumbuhan dan produksi pucuk tanaman kolesom, khususnya pada naungan buatan. Tujuan dari penelitian ini adalah untuk menerangkan respon pertumbuhan dan produk-si pucuk kolesom pada perbedaan tingkat naungan.

\section{Bahan dan Metode}

Penelitian dilaksanakan di Politeknik LPP Yogyakarta, mulai dari bulan Maret hingga September 2016. Penelitian ini menggunakan rancangan acak kelompok (RAK) faktor tunggal dengan 2 taraf perlakuan, yaitu tanpa naungan (N0) dan naungan paranet $82.51 \%$ (N1). Setiap perlakuan diulang tiga kali sehingga terdapat 6 satuan percobaan. Setiap unit percobaan terdiri dari 10 tanaman sehingga total terdapat 60 tanaman. Jumlah sampel tanaman yang diamati untuk pertumbuhan vegetatif adalah 5 (lima) tanaman, sedangkan lima tanaman sisa digunakan untuk pengamatan peubah laju tumbuh relatif dan biomassa tanaman. Pemupukan dilakukan dengan menggunakan pupuk kompos (10 ton/ha).

Bahan tanam yang digunakan pada pembibitan adalah stek kolesom dengan panjang $\pm 10-15 \mathrm{~cm}$ (stek $2 \mathrm{buku}$ ). Pembibitan dilakukan lebih dahulu untuk keperluan bahan tanam agar mendapatkan bibit yang seragam dan dilakukan selama 2 minggu sebelum tanam.

Pembibitan stek batang dilakukan dalam kantong plastik (polybag) yang telah dilubangi dengan media campuran tanah, arang sekam, dan pupuk kandang sapi (2:1:1/v:v:v). Bahan stek diambil dari tanaman induk yang telah dewasa. Stek batang diambil dari bagian tengah batang tua yang telah dibuang daun-daunnya. Pangkal batang dipotong miring kemudian setek ditanam dengan membenamkan $\pm 2 \mathrm{~cm}$ bagian batang ke dalam media semai.

Media tanam yang digunakan untuk transplanting adalah campuran antara tanah dan arang sekam $(3: 2 / \mathrm{v}: \mathrm{v})$. Media tanam tersebut dicampur dengan kompos (50 g/polybag). Media tanam disiapkan dengan memasukkan campuran media tersebut ke dalam polybag kapasitas $10 \mathrm{~kg}$.

Stek batang kolesom ditanam di polybag yang telah berisi media tanam. Penanaman dilakukan apabila bibit yang berasal dari stek batang telah berdaun dua helai dan membuka sempurna ( \pm 14 hari di pembibitan). Setiap polybag ditanam satu tanaman. Bibit yang ditanam tersebut adalah bibit yang memiliki pertumbuhan yang sehat dan seragam di pembibitan.

Kegiatan pemeliharaan tanaman meliputi penyiraman dan penyiangan gulma. Penyiraman dilakukan sekali setiap pada pagi hari pada awal pertumbuhan. Penyiangan gulma dilakukan setiap satu bulan sekali.

Pemanenan dilakukan dua kali (pada umur 6 dan 8 MST/minggu setelah transplanting) dengan melihat kondisi dan kriteria panen daun kolesom. Panen pertama dan kedua dilakukan pada saat daun kolesom telah memiliki kriteria 
panen yaitu dengan memetik bagian pucuk daun dan tiga daun yang membuka sempurna dan menyisakan 2 daun.

Pengamatan dilakukan terhadap (1) tinggi tanaman (cm); (2) jumlah cabang; (3) jumlah cabang sekunder; (4) lebar tajuk; (5) bobot basah dan kering biomassa; (6) laju tumbuh relatif/ LTR; (7) jumlah pucuk per tanaman; dan (8) bobot per pucuk. Untuk peubah pertumbuhan tanaman (tinggi tanaman, jumlah cabang, dan lebar tajuk) diamati pada 1-8 MST. Jumlah cabang sekunder diamati pada 8 MST. Peubah bobot basah dan kering biomassa serta laju tumbuh relatif diamati pada umur tanaman 2-8 MST. Data yang diperoleh diuji dengan menggunakan uji t-student untuk mengetahui perbedaan dari perlakuan yang dicobakan.

\section{Hasil dan Pembahasan}

Tinggi Tanaman. Respon pertumbuhan tinggi tanaman kolesom nyata dipengaruhi oleh perlakuan naungan $(\mathrm{P}<0.05)$ pada umur tanaman 3 MST (Gambar 1). Naungan (intensitas cahaya rendah) menghasilkan tinggi tanaman kolesom yang lebih rendah dibandingkan kolesom yang tidak ternaungi. Hal tersebut karena naungan menghambat pertumbuhan tanaman sehingga tanaman kolesom menjadi tertekan. Saat umur tanaman 6 MST, dilakukan pemanenan pucuk kolesom yang pertama sehingga tinggi tanaman menurun pada umur 7 MST. Secara umum, terjadi peningkatan tinggi tanaman kolesom. Perlakuan naungan menurunkan tinggi tanaman kolesom $11.17 \%$ bila dibandingkan dengan tanpa naungan pada umur 3 MST.

Jumlah Cabang. Respon pertumbuhan jumlah cabang kolesom nyata dipengaruhi oleh naungan $(\mathrm{P}<0.05)$ pada umur tanaman 3 hingga 8 MST (Gambar 2). Perlakuan naungan menghasilkan jumlah cabang kolesom yang lebih sedikit dibandingkan tanpa naungan. Naungan menurunkan jumlah cabang 25.37\% jika dibandingkan dengan tanpa naungan pada umur 8 MST. Penurunan jumlah cabang tersebut diduga karena pertumbuhan tanaman kolesom yang ternaungi dan memperoleh intensitas cahaya yang rendah akan mengalami etiolasi (pemanjangan batang atau ruas tanaman) sehingga pembentukan cabang menjadi berkurang. Etiolasi juga menyebabkan tinggi tanaman yang ternaungi menjadi lebih tinggi karena terjadi akumulasi hormon auksin pada bagian apikal yang tidak terdegradasi oleh cahaya matahari. Hasil penelitian Soverda et al., (2009) menunjukkan bahwa perlakuan naungan $50 \%$ menurunkan jumlah cabang primer tanaman kedelai varietas Lumajang Bewok sebesar $3.4 \%$.

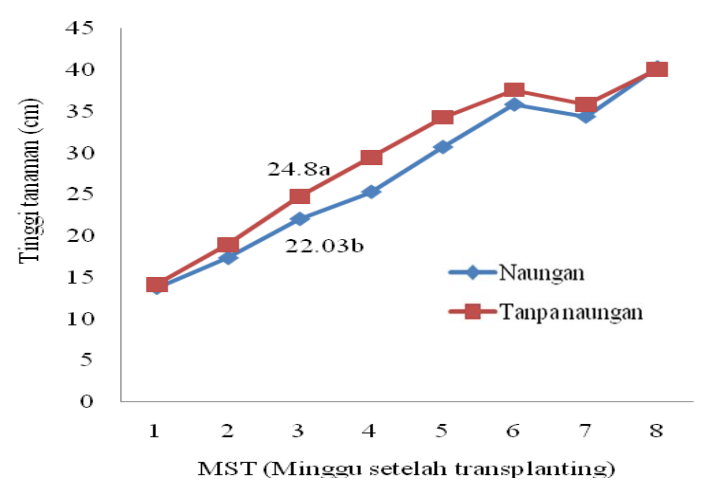

Gambar 1. Respon Pertumbuhan Tinggi Tanaman Kolesom terhadap Intensitas Cahaya Rendah.

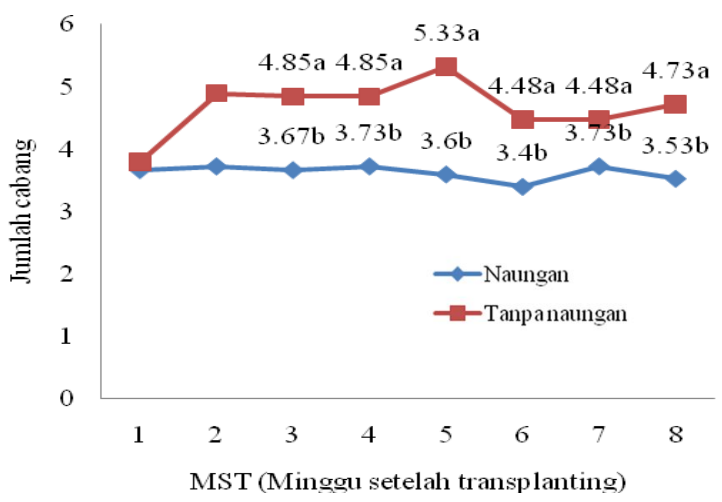

Gambar 2. Respon Pertumbuhan Jumlah Cabang Kolesom terhadap Intensitas Cahaya Rendah.

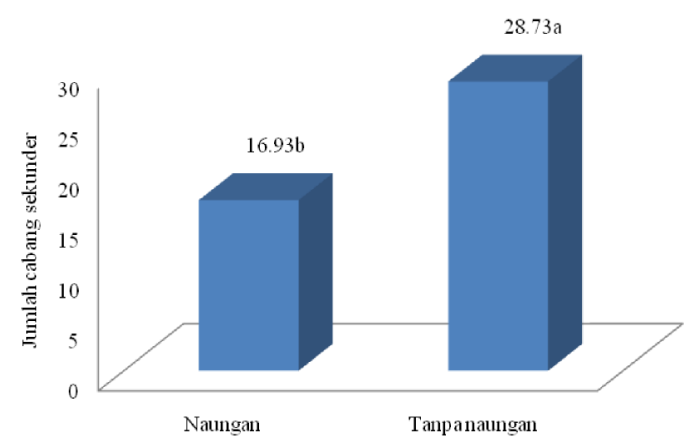

Gambar 3. Respon Pertumbuhan Jumlah Cabang Sekunder Kolesom terhadap Intensitas Cahaya Rendah. 
Pertumbuhan jumlah cabang sekunder kolesom juga nyata dipengaruhi oleh naungan $(\mathrm{P}<0.05)$ pada umur tanaman 8 MST (Gambar 3). Perlakuan naungan menghasilkan jumlah cabang sekunder kolesom yang lebih sedikit dibandingkan tanpa naungan. Naungan menurunkan jumlah cabang sekunder $41.07 \%$ jika dibandingkan dengan tanpa naungan.

Lebar Tajuk. Respon pertumbuhan lebar tajuk kolesom nyata dipengaruhi oleh naungan $(\mathrm{P}<0.05)$ pada umur tanaman 4 dan 7 MST (Gambar 4). Naungan menurunkan lebar tajuk $10.00 \%$ jika dibandingkan dengan tanaman kolesom yang tidak ternaungi pada umur 4 MST. Perlakuan naungan menghasilkan lebar tajuk tanaman kolesom 1.2 kali lebih lebar dibandingkan tanpa naungan pada umur 7 MST. Naungan meningkatkan lebar tajuk 18.03\% jika dibandingkan dengan tanpa naungan pada umur 7 MST. Hal tersebut disebabkan daun tanaman yang ternaungi akan lebih tipis dan lebar daripada daun yang ditanam pada tempat terbuka, yang disebabkan oleh pengurangan lapisan palisade dan sel-sel mesofil (Taiz dan Zeiger, 2002). Intensitas cahaya akan mempengaruhi bentuk dan anatomi daun termasuk sel epidermis dan tipe sel mesofil (Vogelman dan Martin, 1993 dalam Sopandie (2013)). Perubahan tersebut sebagai mekanisme untuk pengendalian kualitas dan jumlah cahaya yang dapat dimanfaatkan oleh kloroplas daun.

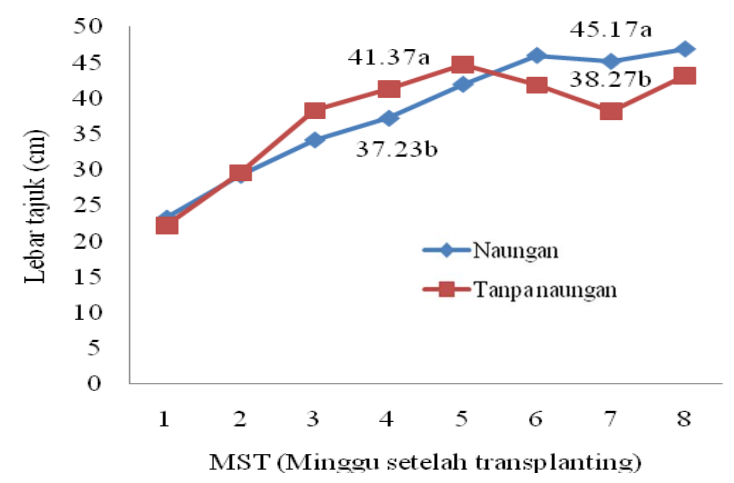

Gambar 4. Respon Pertumbuhan Lebar Tajuk Kolesom terhadap Intensitas Cahaya Rendah.

Bobot Basah Biomassa. Bobot basah biomassa tanaman kolesom dipengaruhi secara nyata oleh perlakuan naungan pada umur tanaman 4 dan 6 MST $(\mathrm{P}<0.05)$ (Gambar 5). Naungan memberikan bobot basah biomassa kolesom yang lebih rendah dibandingkan dengan tanpa naungan. Naungan menurunkan bobot basah biomassa $55.22 \%$ jika dibandingkan dengan tanpa naungan pada umur 6 MST. Bobot basah biomassa kolesom pada perlakuan naungan tidak berbeda dengan tanpa naungan pada umur tanaman 2 dan 8 MST.

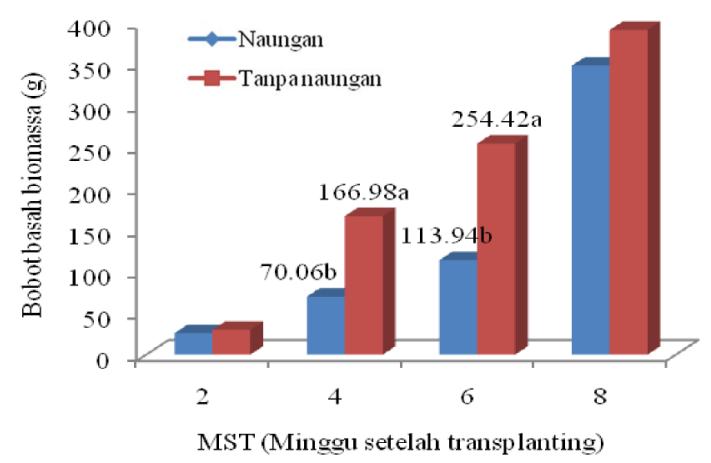

Gambar 5. Pengaruh Intensitas Cahaya Rendah Terhadap Bobot Basah Biomassa Tanaman Kolesom.

Bobot Kering Biomassa. Bobot kering biomassa tanaman kolesom dipengaruhi secara nyata oleh perlakuan naungan pada umur tanaman 4 dan 6 MST $(\mathrm{P}<0.05)$ (Gambar 6). Seperti pada peubah bobot basah biomassa, naungan memberikan bobot kering biomassa kolesom yang lebih rendah dibandingkan dengan tanpa naungan. Naungan menurunkan bobot kering biomassa $68.25 \%$ (umur 4 MST) dan $70.70 \%$ (umur 6 MST) jika dibandingkan dengan tanpa naungan. Bobot kering biomassa kolesom pada perlakuan naungan tidak berbeda dengan tanpa naungan pada umur tanaman 2 dan 8 MST.

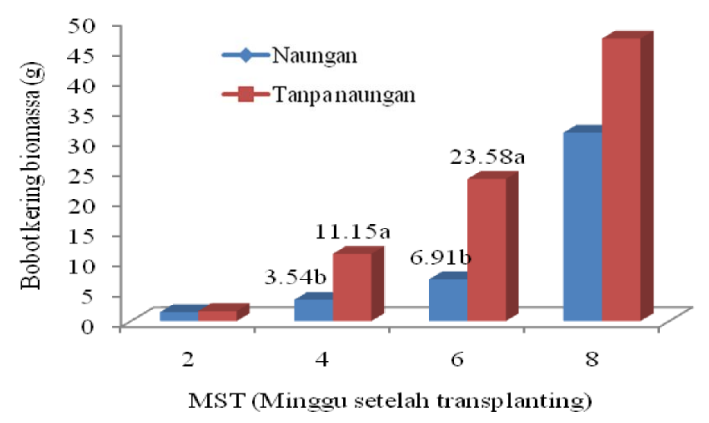

Gambar 6. Pengaruh Intensitas Cahaya Rendah terhadap Bobot Kering Biomassa Tanaman Kolesom.

Secara umum, bobot basah dan kering biomassa kolesom yang ternaungi lebih rendah dibandingkan kolesom yang tidak ternaungi. Hal tersebut karena naungan menyebabkan batang lebih kecil dengan xilem yang kurang berkembang, jumlah cabang yang lebih sedikit, 
helai daun yang lebih tipis dan kadar air tinggi (Daubenmire, 1974). Baharsyah dkk. (1985) menambahkan bahwa penurunan cahaya menjadi $40 \%$ sejak perkecambahan mengakibatkan penurunan jumlah buku, jumlah cabang dan diameter batang sehingga menyebabkan bobot kering tajuk menurun.

Laju Tumbuh Relatif (LTR). Laju tumbuh relatif menunjukkan peningkatan bobot kering dalam suatu interval waktu dalam hubungannya dengan bobot awal. Laju tumbuh relatif tanaman kolesom dipengaruhi secara nyata $(\mathrm{P}<$ 0.05 ) oleh naungan pada periode umur 2-4 MST (Gambar 7). Naungan menghasilkan laju tumbuh relatif yang lebih rendah dibandingkan tanpa naungan. Naungan menurunkan laju tumbuh relatif $49.64 \%$ jika dibandingkan tanaman kolesom yang tidak ternaungi.

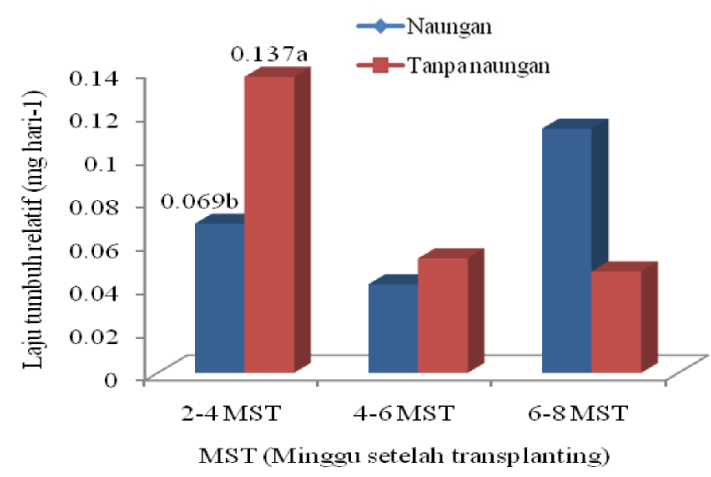

Gambar 7. Pengaruh intensitas cahaya rendah terhadap laju tumbuh relatif tanaman kolesom.

Naungan menurunkan nilai LTR (mg hari-1) pada periode umur 2-4 dan 4-6 MST, namun meningkat pada periode umur 6-8 MST. Hal tersebut menunjukkan bahwa secara umum pertumbuhan tanaman kolesom terhambat dengan adanya naungan pada umur 2-6 MST. Seiring dengan bertambahnya umur tanaman, naungan meningkatkan nilai LTR pada periode umur 6-8 MST. Hal tersebut diduga karena pada periode umur tersebut tanaman kolesom telah memasuki fase dewasa sehingga memiliki hormon pengatur pertumbuhan (plant growth regulator) yang tinggi. Hormon ini antara lain auksin yang menginduksi perpanjangan akar dan dominansi apikal, sitokinin menginduksi pembelahan sel, dan giberelin yang menstimulasi pembelahan dan perpanjangan sel (Hartmann et al., 1990).

Produksi Pucuk Kolesom

Jumlah Pucuk Per Tanaman. Jumlah pucuk per tanaman dipengaruhi secara nyata oleh perlakuan naungan $(\mathrm{P}<0.05)$ pada panen pertama (umur 6 MST) dan panen kedua (umur 8 MST) (Gambar 8). Naungan memberikan jumlah pucuk per tanaman kolesom yang lebih sedikit dibandingkan dengan tanpa naungan. Naungan menurunkan jumlah pucuk per tanaman $40.59 \%$ (umur 6 MST) dan 23.38\% (umur 8 MST) jika dibandingkan dengan tanpa naungan. Hasil penelitian Pratiwi (2013) juga menunjukkan bahwa naungan paranet $75 \%$ menurunkan produktivitas pucuk kolesom sebesar 59\%. Pemanenan berulang dapat mempengaruhi produksi pucuk kolesom karena terjadi peningkatan jumlah pucuk per tanaman yang dapat dipanen mulai dari panen pertama ke panen kedua. Peningkatan tersebut disebabkan munculnya tunas-tunas baru sebagai akibat pemangkasan pucuk pada panen pertama.

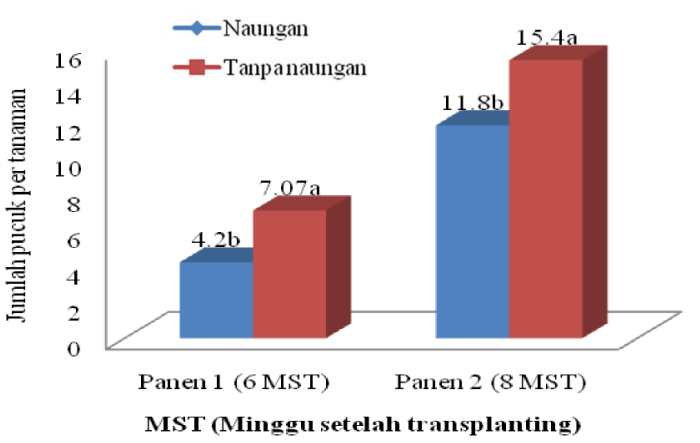

Gambar 8. Pengaruh intensitas cahaya rendah terhadap jumlah pucuk per tanaman kolesom.

Bobot Per Pucuk. Bobot per pucuk kolesom dipengaruhi secara nyata oleh perlakuan naungan $(P<0.05)$ pada panen pertama (umur 6 MST) dan panen kedua (umur 8 MST) (Gambar 9). Naungan memberikan bobot per pucuk kolesom yang lebih tinggi dibandingkan tanpa naungan. Naungan meningkatkan bobot per pucuk $34.56 \%$ (umur 6 MST) dan 29.73\% (umur 8 MST) jika dibandingkan dengan tanpa naungan. Bobot per pucuk mengalami penurunan dari panen pertama ke panen kedua. Hal tersebut diakibatkan karena mengecilnya ukuran pucuk. Bobot per pucuk kolesom yang ternaungi lebih tinggi dibandingkan bobot per pucuk kolesom yang tidak ternaungi. Ukuran pucuk kolesom yang semakin kecil dikarenakan oleh mengecilnya ukuran cabang karena pucuk tersebut berasal dari cabang sekunder. Cabang primer adalah cabang yang muncul dari batang utama, dalam hal ini adalah stek batang yang ditanam. Cabang sekunder adalah cabang yang muncul dari cabang primer. Semakin menge- 
cilnya ukuran cabang juga akan mempengaruhi bobot per pucuk yang dipanen, walaupun jumlah pucuk yang dipanen semakin banyak.

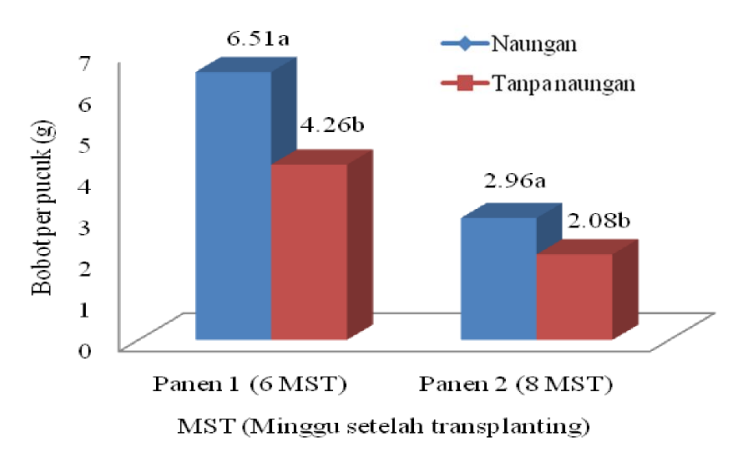

Gambar 9. Pengaruh intensitas cahaya rendah terhadap bobot per pucuk kolesom.

\section{Kesimpulan}

Intensitas cahaya rendah (naungan paranet $82.51 \%)$ pada tanaman kolesom dapat menekan pertumbuhan dan hasil pucuk kolesom. Naungan menurunkan tinggi tanaman, jumlah cabang dan cabang sekunder kolesom. Daun kolesom yang ternaungi lebih lebar jika dibandingkan tanpa naungan. Naungan menurunkan jumlah pucuk, bobot basah dan kering biomassa, tetapi meningkatkan bobot per pucuk kolesom.

\section{Ucapan Terima Kasih}

Terima kasih disampaikan kepada Kopertis Wilayah V Yogyakarta yang telah memberikan dana untuk penelitian ini.

\section{Daftar Pustaka}

Baharsyah, J.S., Suardi, D., Las, I. 1985. Hubungan Iklim dan Pertumbuhan Kedelai, hal 87-102. dalam Somaatmadja, S, Ismunadji, M, Sumarno, Syam, M, Manurung, SO, Yuswadi (Eds). Kedelai. Balai Penelitian dan Pengembangan Pertanian. Pusat Penelitian Tanaman Pangan. Bogor.

Chozin, M.A, D. Sopandie, S. Sastrosumarjo dan Suwarno. 2000. Physiology and genetic of upland rice adaptation to shade. Final Report of Graduate Team Research Grant, URGE Project. Directorate General of Higher Education, Ministry of Education and Culture.

Daubenmire, S. 1974. Plant Environment: a Textbook of Plant Autecology. $3^{\text {rd }}$ edition. New York.

Hartmann, T.H., D.E. Kester and F.T. Davies. 1990. Plant Propagation. $5^{\text {th }}$ Ed. Prentice Hall. New Jersey.

Mualim, L. 2012. Produksi dan kualitas kolesom dengan pemupukan organik dan inorganik. Disertasi. Sekolah Pascasarjana Institut Pertanian Bogor, Bogor.

Salisbury FB dan Ross CW. 1995. Fisiologi Tumbuhan. Jilid 3. ITB Bandung.

Sopandie, D. 2013. Fisiologi Adaptasi Tanaman Terhadap Cekaman Abiotik pada Agroekosistem Tropika. IPB Press. Bogor.

Soverda, N. 2004. Adaptasi tanaman padi gogo terhadap naungan [The adaptation of upland rice to shading]. Jurnal Agronomi. 8 (2): 105-110.

Taiz, L. dan E. Zeiger. 2002. Plant Physiology. The Benyamin/Cummings Pub. Co. Inc. California.

Ververidis, F, E. Trantas, C. Douglas, G. Vollmer, G. Kretzschmar and N. Panopoulos. 2007. Biotechnology of flavonoids and other phenylpropanoid-derived natural products. Part I: Chemical diversity, impacts on plant biology and human health. Biotechnol. J. 10: 1214-1234. 